\title{
Scenario Based Municipal Wastewater Estimation: Development and Application of a Dynamic Simulation Model
}

\author{
Yong Zhang, Tingsheng Zhao, Aijiao Zhou, Zhengzhu Zhang, and Wen Liu \\ School of Civil Engineering \& Mechanics, Huazhong University of Science and Technology, No. 1037, Luoyu Road, \\ Hongshan District, Wuhan 430074, China
}

Correspondence should be addressed to Wen Liu; 379047775@qq.com

Received 29 September 2016; Accepted 7 December 2016

Academic Editor: Luis Carlos Rabelo

Copyright (C) 2016 Yong Zhang et al. This is an open access article distributed under the Creative Commons Attribution License, which permits unrestricted use, distribution, and reproduction in any medium, provided the original work is properly cited.

This paper develops causal loop diagrams and a system dynamics model for estimation of wastewater quantity changes as a function of future socioeconomic development and the municipal water environment of the city under the influence of several key factors. Using Wuhan (a city with population more than 10 million in China) as a case study, the variability of Wuhan's wastewater quantity and water environment is modeled under different development patterns by year 2030. Nine future scenarios are designed by assigning different values to those key factors, including GDP growth rate, water consumption of annual ten thousand GDP, and wastewater treatment fee. The results show that (1) GDP growth leads to an increase in municipal wastewater quantity, but an increase in wastewater treatment fee can be in favor of reducing urban water pollution, and (2) the impact of per ten thousand yuan GDP water consumption on the amount of municipal wastewater is larger in the near future, while the impact of GDP growth rate is much larger in the long term. The dynamic model has proven to be reliable for simulating the municipal wastewater changes, and it could help decision makers to make the scientific and reasonable decisions.

\section{Introduction}

Over the years, a number of methods and models have been developed to explore the links between economy and water demand or wastewater quantity of a city, such as (1) the Environmental Kuznets Curve (EKC) method $[1,2] ;(2)$ Input-Output Model [3-6]; (3) Econometric Methods [7, 8] and Time Series [9, 10]; and (4) Artificial Intelligence Methods [11-13]. However, in these methods, the correlations among different system/process factors and their combined effects on the amount of wastewater are not considered systematically; they are not easy to explain the feedback mechanism(s) among these factors. The system dynamics (SD) method could have great advantages for simulating the future scenarios with simultaneous consideration of the correlations among different system/process factors and their combined effects [14].

System dynamic (SD), originated by Jay Forrester of the Massachusetts Institute of Technology in 1960s, was primarily used in the management of industry and enterprises.
Industrial Dynamics which was published in 1961 is regarded as the classical literary work about SD. Since being originated in 1960s, SD has been applied to more and more research fields. In recent years, $\mathrm{SD}$ also has been used in the research of water resource, water environment, and urban water supply. Xi and Poh [15] researched the sustainable water resources management in Singapore by using SD. Davies and Simonovic [16] discussed the global sustainable water resources and developed an integrated SD model that involves social, economic, and environmental subsystem. Ahmad and Prashar [14] applied SD model to evaluate the effectiveness of the municipal water conservation policies. For water environment, Guo et al. [17] utilized a SD model to plan the environmental management system of the basin and tested four planning alternatives that was desired for sustainable for regional development. Zhu et al. [18] investigated the influence of the total nitrogen (TN) and total phosphorus (TP) concentrations in socioeconomic water on the Normalized Difference Vegetation Index (NDVI) and the feedback mechanism among them, which could help to promote the 
water quality and the ecological functions in Baiyangdian Lake, of China. For water supply, Sahin et al. [19] researched the effect of water price in dealing with the water scarcity when suffering temporary drought and SD modeling could help the planners to formulate reasonable price regime and scheme water supply infrastructure. Zarghami and Akbariyeh [20] established the SD model for the complex urban water system of Tabriz, which comprehensively considered the potential water supply resources as potential sources of demand for water resources and corresponding management measures. Dawadi and Ahmad [2] concerned the influence of climate change, population growth, water price, and water management policies on the water resources in Las Vegas, and SD model that integrated the abovementioned factors was developed to simulate changes in the urban water supply and demand in a long term in future under implementation of the policies. Compared with the forecast of water consumption, wastewater forecasting has its own characteristics. For example, the irrigation water demand is huge, but it actually seeps into underground or flows into rivers through surface runoff, and due to the imperfectness of wastewater network, collected agricultural wastewater is finite; and deterioration of water environment pushes the government to make more stringent standards to restrict the emission of wastewater.

Urban wastewater that contains large amount of organics (including nitrogen and phosphorus), inorganics, and varieties of bacteria and viruses is mainly composed of domestic wastewater and industrial wastewater. In the aspect of wastewater treatment technologies, biological treatment processes, such as activated sludge and biofilm, are widely used for the good biodegradability of urban wastewater. According to the requirements of water quality, physicochemical methods, such as coagulation, precipitation, and membrane filtration, can be combined with biological technologies to further improve treatment effect. In the generation of wastewater, information exchanges and material communications among different factors (such as population and socioeconomic growth) can affect the amount of municipal wastewater. And previous studies neglected the correlations among different factors and their combined influences on the amount of wastewater. On the whole, both domestic water consumption forecast and industrial water consumption forecast by SD approach have been reported. But there are a few studies taking into account the dynamic changes of municipal wastewater and its influence on basin environment and regional economic development.

In light of the aforementioned analysis, a SD method is proposed in this study to research the dynamic changes of municipal wastewater and municipal water environment under different policies for socioeconomic development. The objectives of this work are to (1) develop a SD model for analyzing long-term fluctuations in the amount of municipal wastewater under the influence of socioeconomic factors and the dynamic relationship among them and (2) through case studies verify and calibrate the SD model developed and the further use it to simulate changes in municipal wastewater quantity under different patterns of economic development.

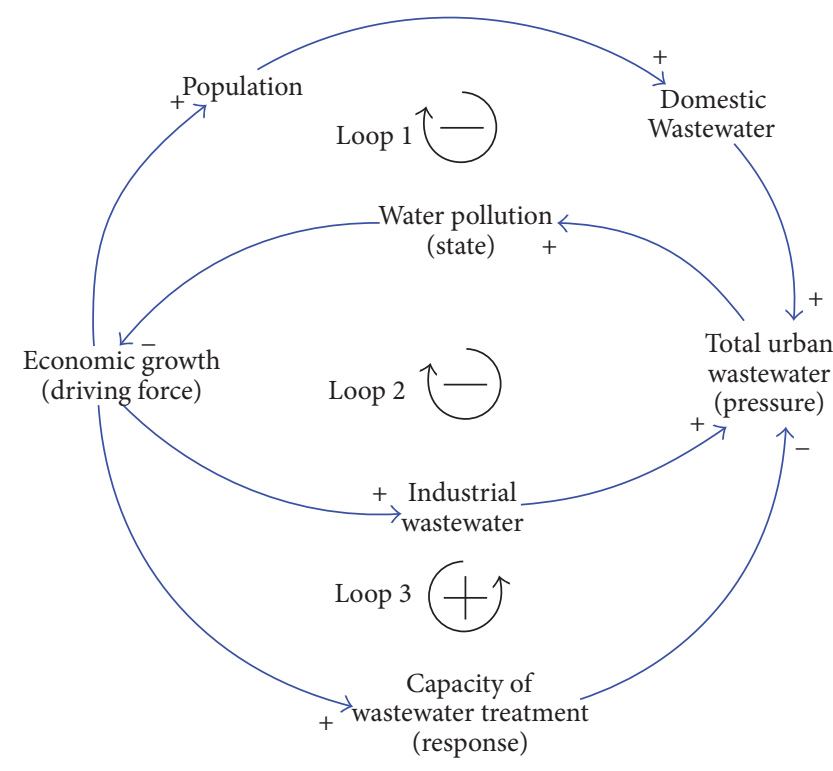

Figure 1: The causal loop diagram of the model.

\section{Method}

\subsection{Development of SD Model}

2.1.1. System Boundary. This study mainly explores the fluctuation of municipal wastewater under the different development patterns and investigates the complex relationship among economic development, municipal wastewater, and water pollution system. In this model, municipal wastewater is forecasted though the economy and population level, and water pollution is caused by the discharge of untreated wastewater, and the quantity of untreated wastewater depends on the capacity of wastewater collection and disposal of the city. The above three parts are the system boundaries and form the system of "economic developmentmunicipal wastewater-water pollution," which is the main structure of the model. Besides, the time bound of the SD model is from the year of 2000 to 2030, and the time step is 1 year.

2.1.2. Causal Loop. The system boundary is briefly described in the previous section, and numerous factors have influence on the system of "economic development-municipal wastewater-water pollution." The main factors affecting the behavior of the system are to be identified based on the logic thinking of "Pressure-State-Response." A causal loop diagram is established to describe the dynamic behavior of the entire model. According to the basic principle of $\mathrm{SD}$, three feedback loops are proposed in the causal loop diagram, among which two are negative and one is positive. As shown in Figure 1, loop 1 is a negative feedback loop. This loop starts from the economic development, which attracts more people into the city; the increase of population inevitably leads to the increase demand of domestic water and the increase of domestic wastewater which is a major part of the total municipal wastewater, thus increasing the total amount of wastewater. As a result, the pollution of 


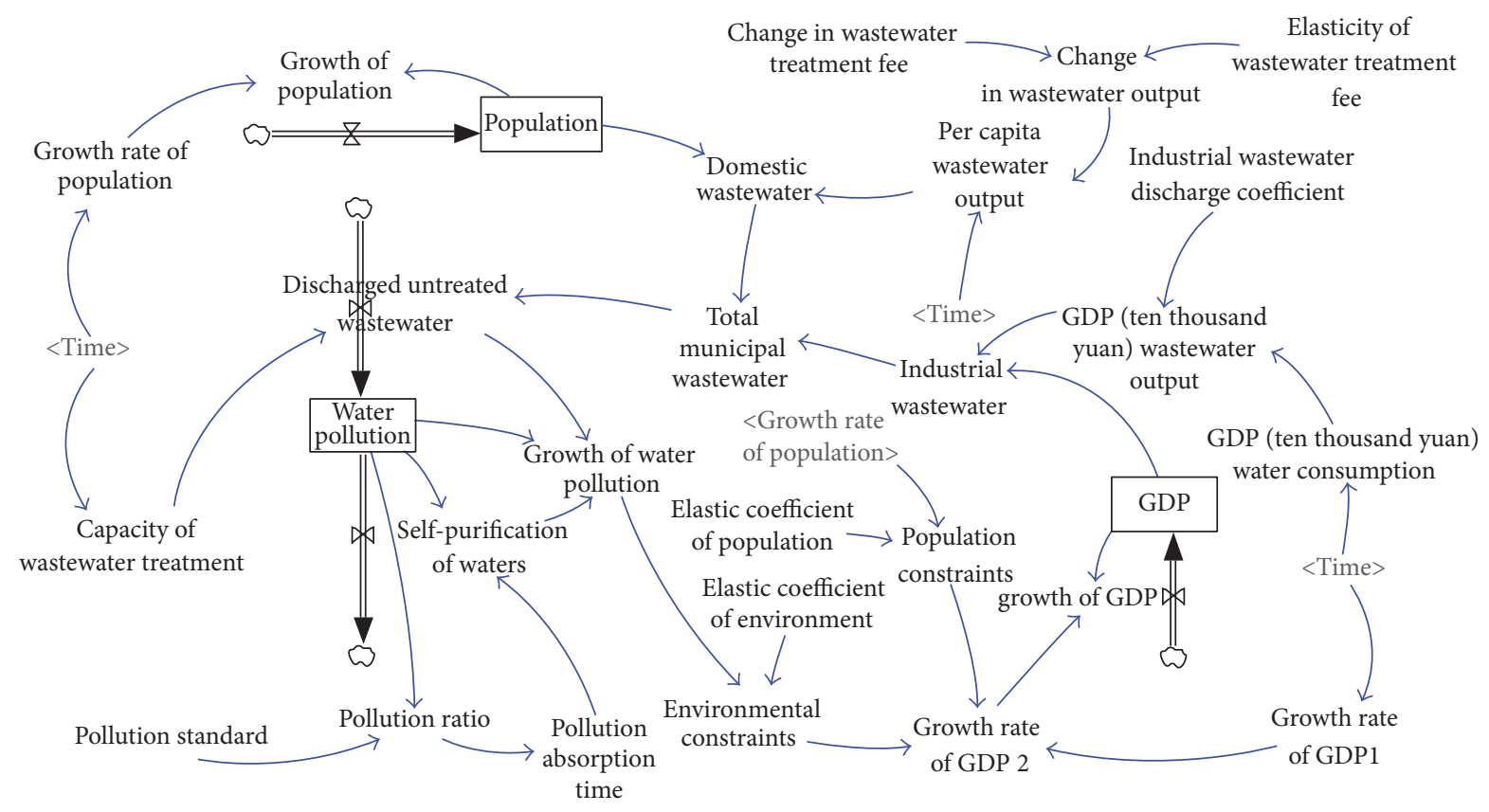

FIGURE 2: The stock-flow diagram of the model.

natural water body is exacerbated. And in reverse, water pollution can indirectly hinder the economic development. Therefore, the factor economic growth can affect itself through the negative feedback chain. Loop 2 is a negative feedback loop as well. In terms of economic growth element, the increase of population enlarges the labor resources that accelerate the economic growth; thus the industrial water use increases as economic growth speeding up. Finally, the industrial wastewater increases. As it is in loop 1 , the variables affect itself negatively by the feedback mechanism. Loop 3 is a positive feedback loop, which is about capacity of municipal wastewater treatment. The economic development promotes the development of industries related to wastewater and the investment of wastewater treatment increases then. Consequently, the capacity of wastewater treatment can be largely improved. The wastewater discharged directly into water bodies can be reduced; namely, the water pollution diminishes. It can be seen that the abovementioned three feedback loops eventually contain the feedback of the environmental pollution on economic development. This is the first attempt to take into account the retarding effect of water pollution on the development of regional economy which is usually neglected by other researches using SD model.

The model structure is visually described through the causal loop diagram that preliminarily reflects the dynamic relationships of the wastewater forecast and management system. Though the causal loop diagram cannot represent the whole system and it is only a rough description of the system structure, it is essential for building a formal model (the stock-flow diagram).

2.1.3. Stock-Flow Diagram. Those cited in the causal loop diagram are the primary variables that control the behavior changes of the system, which are not the whole of the wastewater forecast and management system, and the nature of different variables cannot be distinguished through the causal loops diagram. Therefore, more variables and flow need to be added to complete the SD model; thus it is necessary to draw the stock-flow diagram which highlights the role of the stock and the flow rate in the entire system. Stock, the most important element in system dynamics, reflects a process of accumulation. Flow, reflecting the input and output rate of the stock, is the variable that affects the value of the stock directly through changing the rate of accumulation process. In this study, the modeling software is Vensim. The stock-flow diagram is shown as Figure 2.

Some necessary explanation and assumptions for the SD model established in this study are as follows:

(a) Municipal wastewater treatment capacity is one of the key factors that determine whether water pollution can be effectively controlled. Though the wastewater treatment capacity is largely influenced by the investment of wastewater treatment industry and economic development, it is regarded as a variable that only changes over time and can be controlled by the policy makers.

(b) Wastewater is divided into two categories depending on its source: domestic wastewater and industrial wastewater. Although the irrigation water demand is huge, most of agricultural wastewater, especially no-point wastewater, actually seeps into underground or flows into rivers through surface runoff. Due to the imperfectness of wastewater network, most agricultural wastewater could not be collected into wastewater treatment plants. The real amount of agricultural wastewater that gets into wastewater network 
is finite. In this model, agricultural wastewater is excluded.

(c) In cities, separate sewers drainage system are constructed in overwhelming majority of new districts. Rainwater is collected separately, and most of the collected rainwater is discharged directly into natural water bodies, while the wastewater is delivered to the wastewater treatment plant. But the combined sewers still exist in some old districts, which can be divided into two types: intercepting combined sewers and direct-discharging combined sewers. Due to water pollution caused by combined sewers, more and more combined sewers are reformed to implement rainfallwastewater separation in old communities nowadays. Therefore, the amount of rain does not appear as a variable in the SD model.

(d) In this study, there are three state variables in SD model: GDP (Gross Domestic Product) standing for the economic development; population referring to the resident population in Wuhan; water pollution equivalent to the amount of discharged wastewater. Besides, there are four rate variables: growth of $G D P$ which controls the changes of GDP; growth of population which changes the population size; discharged wastewater that is untreated changes the pollution degree of waters; and self-purification of waters. In addition, there are many auxiliary variables whose values are calculated according to other variables in the system. And there are four constants: per capita water use quota, discharge coefficient of domestic wastewater, discharge coefficient of industrial wastewater, and pollution standard. According to the objective of this study, the model can be divided into three parts: wastewater forecast, water pollution, and pollution control. They are interrelated and interacted and jointly determine the dynamic behavior of the system.

\subsubsection{Major Equations}

(1) Population. Population is one of the main driving factors of municipal water consumption. When per capita water use quota is constant, the population growth directly results in the growth of municipal water consumption, inevitably leading to the growth of wastewater. The factors affecting the size of population include the birth rate, death rate, immigration, and emigration, but only the net rate of population growth is considered in this study. The data comes from Wuhan Statistical Yearbook. The initial time set by the model is the year of 2000, in which the population of Wuhan was $8,0481,000$, that is, the initial value of population. In the time bounds of the model, the annual value of population is determined by following equations:

$$
\operatorname{Pop}(t)=\operatorname{Pop}\left(t_{0}\right)+\int_{t_{0}}^{t} \operatorname{growth}(t) d t
$$

where $\operatorname{Pop}(t)$ is the population at time " $t$ ", growth $(t)$ is the population growth at time " $t$ ", and $t$ is the simulation step, in one year.

(2) GDP. Economic development is equivalent to economic growth, which is illustrated by Gross Domestic Product (GDP) in most literature. Neoclassical growth theory suggests that GDP growth is the result of the capital accumulation, the increase of labor, and the technological change acting in a long term. But the new theory of economic growth regards the labor as labor capital investment, including not only the absolute number of the labor force, but also the education level and production skills, and so forth. They are the production factors of during the economic growth. Certainly, they do not represent all production factors which also include the land and entrepreneurs. Regional economy cannot grow without the aggregation of production factors, and the aggregation of those factors brings the industry aggregation, thus promoting regional economic prosperity. Some scholars have clearly stated that the economic development is equivalent to the aggregation. However, more and more researches pay attention to regional economic development under the constraints of economic resources and environmental in recent years. In other words, resources and environment are also the important production factor that shall be taken into account when using the production function. In this paper, the influence of population and negative impact of environmental pollution on the economic growth are considered in the SD model for the first time. Population means labor resources, which is the most important production factor. Although whether the influence of population on the economic development is favorable, there is no consensus in different literatures. But on the whole, the economy of China is developing rapidly while China's population growth rate is declining, and the reason is that China has a large size of population and enjoys a huge demographic dividend.

The resource abundance of a region and environmental quality can limit the economic growth of the region. Total Factor Productivity (TFP) [22] considers resources and environments certainly lower than traditional productivity excluding resources and environment. In that way, economic growth slows down. Additionally, Nordhaus and Weitzman [23] first proposed the notion of growth drag and explained it as the reduction degree of per capita output growth rate with the resource constraints comparing with that without the resource constraints. Bruvoll et al. [24] clearly put forward the notion of environmental drag and considered that environment pollution could reduce the economic output of a region and the well-being of consumers. A dynamic Computable General Equilibrium (CGE) model was developed in their study to measure the damage extent of environmental constraints to Norwegian residents' welfare. Chinese scholars have also studied the "blocking effect" of environmental pollution to the regional economic development. Zhang et al. [25] illustrated the longterm dynamic relationships between the industry wastewater and industrial solid waste and the economic development by a VAR model in Guanzhong, Shanxi. It was found that 
the environmental pollution has obvious restraining effect on the economic development of Guanzhong. Li [26] has also measured the "blocking effect" on Chinese economic growth under the environmental constraints with a mean value of $0.44 \%$; namely, Chinese economic growth declines $0.44 \%$ per year in the presence of resource and environmental constraints. The constraint of resources and environment is an objective reality, but neither resource nor environment was considered as a factor of production in traditional statistical methods of economic growth. Therefore, this study suggests that the environmental pollution pays negative impacts on the economic growth. Coordinated development of economy and environment is the essence of sustainable development; SD model of this article takes negatively effect of the environmental deterioration to the economic development into consideration, which directly reflects in the dragon GDP growth. The value of GDP is calculated by the following equations:

$$
\begin{aligned}
\operatorname{GDP}(t) & =\operatorname{GDP}\left(t_{0}\right)+\int_{t_{0}}^{t} \operatorname{Growth}(t) d t, \\
\operatorname{Growth}(t) & =\operatorname{GDP}(t) \times \operatorname{rate}_{2}(t), \\
\operatorname{rate}_{2}(t) & =\text { rate }_{1}(t) \times\left(1+e_{1}\right)\left(1-e_{2}\right),
\end{aligned}
$$

where GDP $(t)$ is GDP at time " $t$ ", Growth $(t)$ is GDP growth at time " $t$ ", $t$ is the simulation step, in one year, rate $_{1}(t)$ is the growth rate without constraints, $\operatorname{rate}_{2}(t)$ is the growth rate under constraints, $e_{1}$ is the influence coefficient of population to economy, and $e_{2}$ is the influence coefficient of environment to economy.

(3) Water Pollution. For the pollution degree of natural water bodies in the study region, only the influence of untreated municipal wastewater is considered according to the foregoing assumptions. The receiving water of that region is regarded as a whole and the pollution degree depends on the stock of wastewater in the waters that is determined by the amount of untreated wastewater and self-purification of waters. Specifically, the removal of pollutant depends on the stock of water pollution and pollution absorption time (pat) that represent the time spent in entirely removing a certain amount of contamination. So the amount of water selfpurification for each unit of time is the ratio of water pollution and pollution absorption time. In this study, pat is a nonlinear function of the pollution ratio (polr). Lookup function in Vensim software is used to build an equation to describe the nonlinear relationship. Pollution ratio, represented by the water pollution and pollution standard (pols), is the characterization of the pollution levels. The main equations in this part are as follows:

$$
\begin{aligned}
\operatorname{Pol}(t) & =\operatorname{Pol}\left(t_{0}\right)+\int_{t_{0}}^{t}[\operatorname{dis}(t)-\operatorname{pur}(t)] d t, \\
\operatorname{pur}(t) & =\frac{\operatorname{Pol}(t)}{\operatorname{pat}(t)}, \\
\operatorname{polr}(t) & =\frac{\operatorname{Pol}(t)}{\operatorname{pols}},
\end{aligned}
$$

where $\operatorname{Pol}(t)$ is the value of water pollution at time " $t$ ", dis $(t)$ is the amount of untreated wastewater at time " $t$ ", $\operatorname{pur}(t)$ is the water self-purification at time " $t$ ", and $t$ is the simulation step, in one year.

(4) Wastewater Treatment Fee. The increase of water price can generally reduce the water demand [27]. Furthermore, the price leverage can ease the contradiction between water supply and demand. Wastewater treatment fee generally consists of two parts, namely, the government subsidy and the actual payment by polluters. The range of wastewater treatment fee that the residents in Chinese capital city actually pay is from 0.3 to 1.4 yuan $/ \mathrm{m}^{3}$, which accounts for $14 \%$ to $46 \%$ of living water price. Industrial wastewater must be treated to meet the water quality discharge standard before discharged into the urban wastewater pipe network, and its treatment fee is the same as that of domestic wastewater. The wastewater treatment fee in Wuhan was 0.8 yuan $/ \mathrm{m}^{3}$ before August 1, 2015, thereafter 1.1 yuan $/ \mathrm{m}^{3}$, rising 37.5\%. Municipal wastewater treatment fee has not received adequate attentions because it is included in the actual water charges. To increase the wastewater treatment fee can reduce the discharge of municipal wastewater, thereby cutting down the burden of municipal wastewater treatment system which is caused by the growing amount of wastewater. And what should be particular of concern is how much the rise of wastewater treatment fees can lead to the wastewater reduction. The double logarithmic analysis model [28] is commonly utilized to decide the price elasticity of water demand water:

$$
\ln w=\alpha \ln p+\gamma \ln y+\eta
$$

where $w$ is water demand, $p$ is water price, $y$ is household income, and $\eta$ is errors.

The impact of water price and household income on water demand is considered in this model and $\alpha$ and $\gamma$ are the price elasticity and income elasticity. In this paper, the model above is simplified to get the equation for the quantitative relationship between the increase of wastewater treatment fee and the changes of wastewater:

$$
c=\left(\frac{p_{2}}{p_{1}}\right)^{\alpha},
$$

where $c$ is the coefficient of wastewater variation, $\alpha$ is the wastewater price elasticity, $p_{1}$ is the current wastewater treatment fee, and $p_{2}$ is the adjusted wastewater treatment fee.

2.2. Model Validation. According to Barlas [29], the ultimate objective of system dynamics model validation is to test the validity of the structure of the model which can be classified as two types, namely, direct structure test and structureoriented behavior test. To test direct structure validity of the model, we have checked that whether the model includes all important variables that are to be investigated. The SD model developed in this study is to simulate the changes of municipal waste water under the socioeconomic development and the scenarios after some related policy implemented. Simultaneously, to find out whether the feedback 
relationship is illogical, the correctness of the relationships between variables must be checked. Eventually, it is found that the SD model for wastewater forecast and management not only meets the modeling purpose, but also guarantees the completeness and accuracy of the relationship between the variables. In the model with numerous variables and complex causal loops, units of these variables and their quantitative relationships in the equations are fallible. Unit check can ensure the consistency of variables in the causal chain. When Vensim warns an error in checking units, it is necessary to reassign unit for the variable that has wrong unit. If the error still exists, all the other variables related to that variable should be checked to assure they are defined correctly.

After completing the SD model and model validation, a case study in Wuhan is carried out. In the next section, the study region is introduced and the variables are assigned; then the simulation for status quo is conducted in order to calibrate the SD model established previously. In the end, the scenarios of different future development patterns are designed for the scenario analysis.

\section{Case Study}

3.1. Study Region. Wuhan, the capital of Hubei province, is located in central China. Wuhan has a vast land of $8,494.41 \mathrm{~km}^{2}$ and a population of $102,200,000$ [30], which is subject to a typical north subtropical monsoon climate with four distinctive seasons, abundant rainfall, and heat, with annual temperature of $15.8^{\circ} \mathrm{C}-17.5^{\circ} \mathrm{C}$. Wuhan is rich in water resources and has a total water area of $2,217.6 \mathrm{~km}^{2}$ accounting for $26.1 \%$ of the city's land [31]. However, the adequate water resources and relatively cheap price lead to low efficiency of water utilization and low wastewater reuse rate which result in a huge amount of wastewater output. This is contrary to the resource conservation policy advocated by the government, and a more serious problem is that wastewater output increases as a result of the low utilization rate of water resource. Currently, 12 wastewater treatment plants with a total capacity of $1,885,000$ tons per day have been built in the main city of Wuhan so far. The amount of wastewater changes drastically under different policies, which would bring enormous pressures on the collection, treatment, planning, and management of municipal wastewater.

3.2. Values of Variables. There are three level variables in the SD model, namely, population, GDP, and water pollution, whose initial values need to be set. The initial value of population and GDP is $8,048,100$ and 1.20648 billion which is based on the statistical data of 2000 , the starting year of this model. The values of population growth rate, GDP growth rate, and water consumption of annual ten thousand GDP are extracted from historical statistics from 2000 to 2012. The data is from the Wuhan Statistical Yearbook [32] during the period from 2000 to 2012 . The initial value of pollution is assumed to be 1 in 2000 . In this study, the population elasticity to GDP, $e_{1}$, is set as 0.2 ; namely, each $10 \%$ population growth results in $2 \%$ GDP growth. The coefficient environmental drag to GDP growth, $e_{2}$, is set as 0.12 [25]. The elasticity of

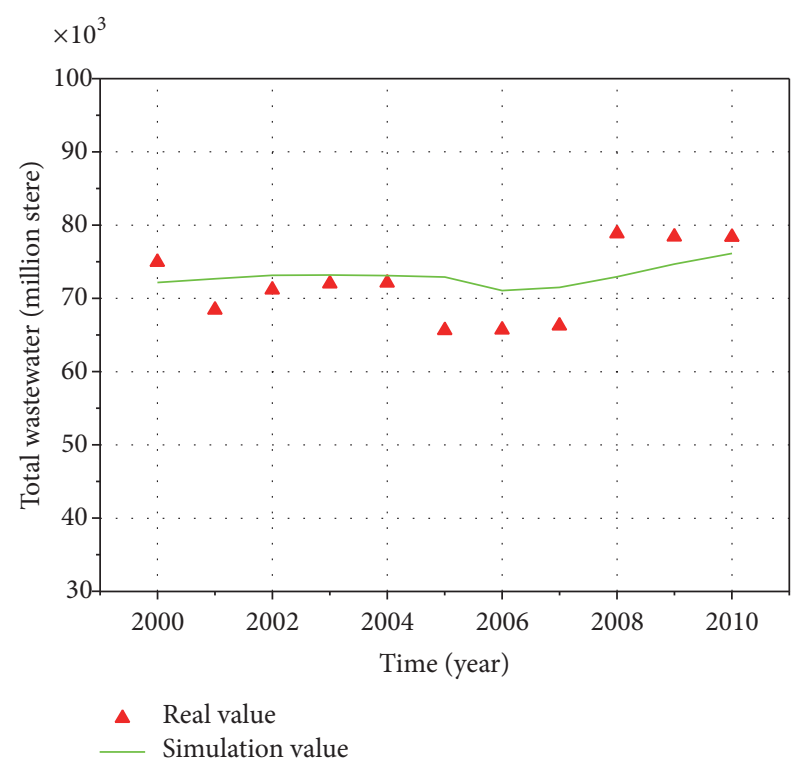

FIGURE 3: The comparison of the real value and the simulation value.

wastewater treatment fee for wastewater output $\alpha$ is set as 0.1 . The initial values of the variables and the main parameters in the SD model are listed in Table 1.

3.3. Model Calibration. The simulation results of status quo simulation were compared with the historical statistical data to evaluate the reliability of the SD model. Based on the guidelines of "the process of estimating the model parameters (structure) to obtain a match between observed and simulated structures and behaviors [as] a stringent test of a hypothesis linking structure to behavior" [33], a sensitivity analysis was conducted and the wastewater system in Wuhan during 2000-2010 was simulated with the model. The mean absolute percentage errors (MAPE) between the simulated data and the historical data are shown in Table 2. The average of MAPE is $5.25 \%$ for the amount of treated wastewater. Figure 3 shows the comparison between the simulated data and real values of the amount of treated wastewater. As can be seen, the trend of simulated values coincides with the real values during the period of 2000-2010 during which the statistical data are available. These results indicate that the model can effectively simulate the real municipal wastewater system, and thus it is reliable.

\subsection{Simulation Results}

3.4.1. Simulation Results of Status Quo. Status quo simulation results of total wastewater have been shown in last section, and Figure 4 shows the comparison of total wastewater (TW) and wastewater treatment capacity (WTC). The maximum difference between those two variables appears in the period of 2000 to 2002 and decreases yearly. This gap flattens after the wastewater treatment capacity increasing sharply by the year of 2007. In fact, the government of Wuhan had been aware of the seriousness of pollution and constructed a number of wastewater treatment facilities making use of 
TABLE 1: Details of the parameter values used in the SD model.

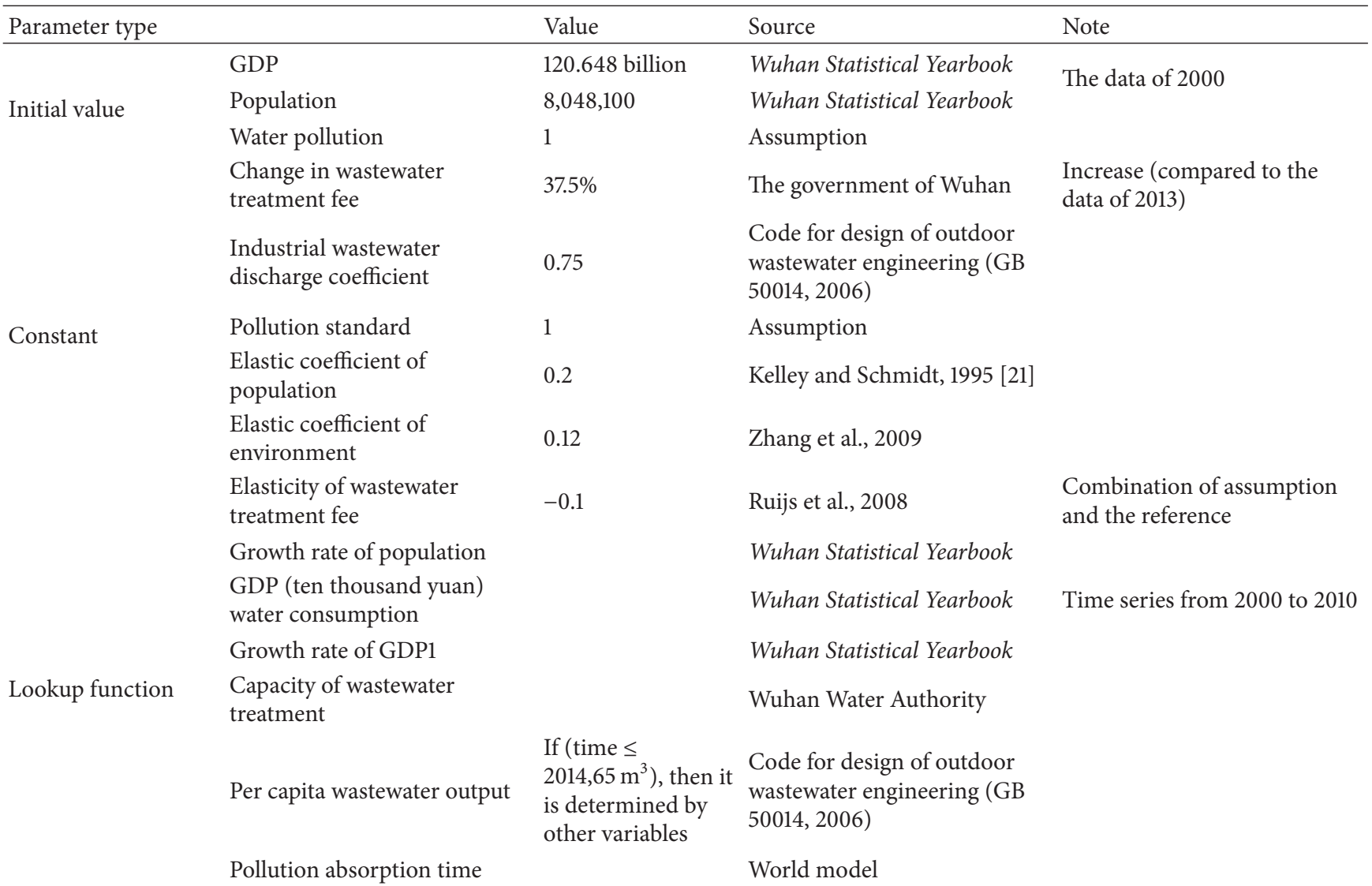

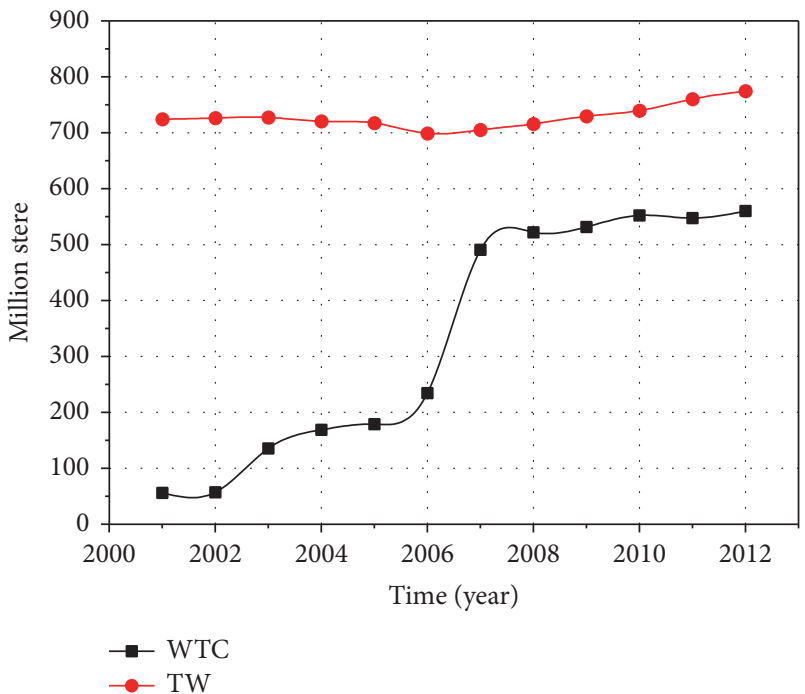

FIGURE 4: The comparison of wastewater treatment capacity and total wastewater.

Asian Development Bank (ADB) loans and other funds from 2001. So the gap between the wastewater treatment capacity and the amount of wastewater was becoming smaller. But there is still a gap of 200 million tons by the year of 2012. As a result, a large amount of untreated wastewater was discharged into the receiving waters, which

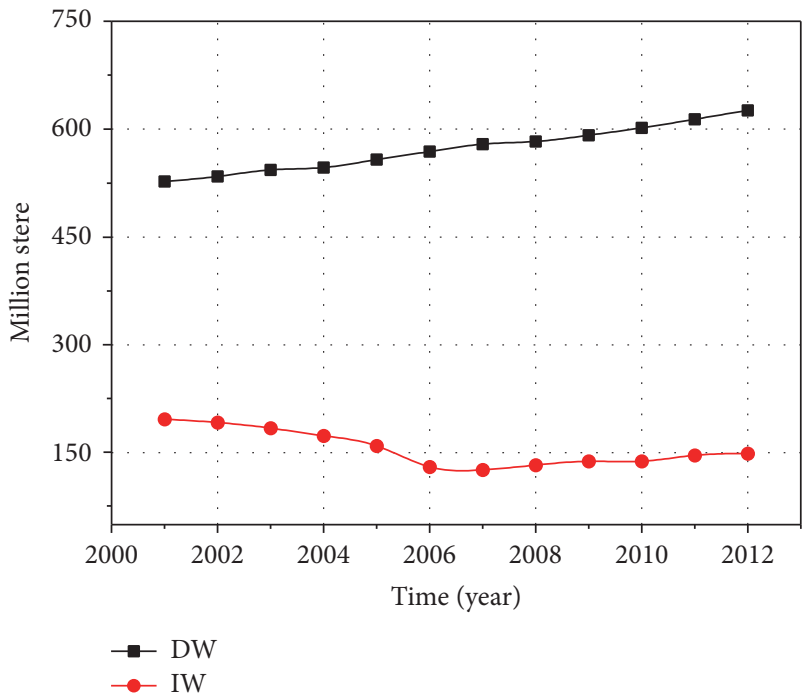

FIGURE 5: The component of total wastewater: domestic wastewater (DW) \& industrial wastewater (IW)

has an extremely negative impact on the urban water environment.

Figure 5 shows the trend of domestic wastewater and industrial wastewater; we can see that domestic wastewater rises slowly and makes up a major part of municipal wastewater, accounting for more than $60 \%$ of the total wastewater. 
TABLE 2: The comparison of the real value and the simulation value.

\begin{tabular}{lccc}
\hline Year & The real value & The simulation value & MAPE (percent) \\
\hline 2000 & 74971.03 & 72183.4 & 3.72 \\
2001 & 68456 & 72681.8 & 6.17 \\
2002 & 71189.72 & 73146 & 2.75 \\
2003 & 72026.27 & 73193.8 & 1.62 \\
2004 & 72144.77 & 73116.1 & 1.35 \\
2005 & 65665.27 & 72926.5 & 11.06 \\
2006 & 65746.34 & 71075 & 8.10 \\
2007 & 66283.2 & 71488.1 & 7.85 \\
2008 & 78858.76 & 72973.3 & 7.46 \\
2009 & 78435.06 & 74689.8 & 4.77 \\
2010 & 78376.66 & 76127 & 2.87 \\
\hline
\end{tabular}

TABLE 3: The design of scenarios.

\begin{tabular}{lccc}
\hline Scenarios & Growth rate of GDP (\%) & Water consumption of annual ten thousand GDP $\left(\mathrm{m}^{3}\right)$ & Increase of wastewater treatment fee $(\%)$ \\
\hline 1 & 10 & 35 & 37.5 \\
2 & 10 & 25 & 37.5 \\
3 & 8 & 35 & 37.5 \\
4 & 8 & 35 & 50 \\
5 & 8 & 35 & 100 \\
6 & 8 & 30 & 37.5 \\
7 & 8 & 25 & 37.5 \\
8 & 6 & 35 & 37.5 \\
9 & 6 & 25 & 37.5 \\
\hline
\end{tabular}

Also, it can be seen that there is a downward trend for industrial effluent over time.

3.4.2. Scenario Design. Scenario analysis can also be called policy simulation, which treats some major factors as the control variables; their values are to be adjusted to form different simulation schemes. This simulation tests the policies in the period of 2015 to 2030 . The goal of resource-saving and environment-friendly society is to obtain rapid economic growth in the case of low resource consumption and less waste generation. The economic growth is characterized as the growth of GDP, and resource conservation in this article mainly refers to reducing the industrial water consumption. Thus three main factors are chosen as scenario variables for the scenario analysis, namely, GDP growth rate, water consumption of annual ten thousand GDP, and wastewater treatment fee. The different assignments of each variable constitute different future scenarios, which are listed in Table 3.

Scenarios 1 and 2. These two scenarios represent the future scenario of municipal wastewater under rapid economic development; that is, the average annual growth rate of GDP is $10 \%$ in Wuhan during the period of 2015-2030. For the water consumption of annual ten thousand GDP, two levels are set in these two scenarios. Namely, the water consumption of annual ten thousand GDP is set as $35 \mathrm{~m}^{3}$ (current level) and $25 \mathrm{~m}^{3}$ by the year of 2030 . The increase of wastewater treatment fee is $37.5 \%$ (compared to the data of 2014) which was adjusted by the government in 2015 .

Scenarios 3 7. The future municipal wastewater is simulated under the moderate pace of economic development, and the average annual growth rate of GDP is set as $8 \%$ which is the current GDP growth rate of Wuhan. The impact of resource conservation and wastewater treatment fee on municipal wastewater are investigated in these scenarios. In scenarios 3 5, only the increase of wastewater treatment fee is changed, while the input value of water consumption of annual ten thousand GDP is set as $35 \mathrm{~m}^{3}$, the current level. Three different levels are set for the increase of wastewater treatment fee; one is $37.5 \%$; the second is $50 \%$ which is higher than the current; the last is the highest, 100\%. In scenario 6 and scenario 7 , the industrial water consumption of annual ten thousand GDP is set as $30 \mathrm{~m}^{3}$ and $25 \mathrm{~m}^{3}$, respectively, while the increase of wastewater treatment fee is set as the current value, $37.5 \%$.

Scenarios 8 and 9. Scenarios 8 and 9 are the analysis of future municipal wastewater under the economic growth of a low speed while the values of other variables are the same as scenarios 1 and 2 . The average annual growth rate of GDP drops to $6 \%$. Scenario 8 is the modeling of the response to policies changes under the development pattern of low 


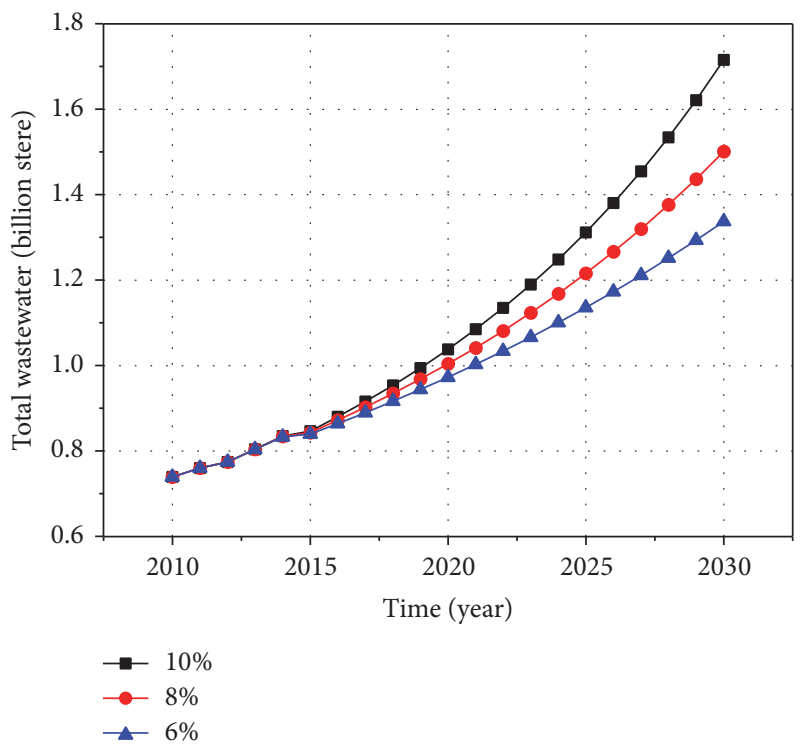

Figure 6: Total wastewater under different GDP growth rate.

growth and high consumption. On the contrary, scenario 9 is to simulate the dynamic change of the entire system under the scenario of a low growth and low consumption.

\subsubsection{Simulation Results of Future Scenarios}

(1) GDP Growth Rate. Wuhan is a central developing city and the GDP growth is always regarded as one of the most important indicators of social development. However, rapid growth of GDP is pursued while environment issues are ignored, even at the expense of the environment. In this section, the influence of GDP growth to the wastewater amount and water environment is analyzed. Figure 6 shows the change of the amount of municipal wastewater under different GDP growth rate $(10 \%, 8 \%$, and 6\%) while the other factors are constant. Obviously, there is a positive correlation between the GDP growth rate and the amount of municipal wastewater. The growth of GDP leads to the growth of municipal wastewater, and greater GDP growth leads to faster growth in wastewater. On the basis of $10 \%, 8 \%$, and $6 \%$ GDP growth rate, the total amount of wastewater in 2030 increase by $50.6 \%, 43.8 \%$, and $37.2 \%$, respectively, compared to that in 2015. Compared to the current GDP growth rate $8 \%$, when GDP growth rate increases to $10 \%$, the total amount of wastewater by 2030 increases by $14.3 \%$, and when it decreases to $6 \%$ that would decrease by $10.8 \%$.

As shown in Figure 7, the urban water pollution is analyzed in the situation that the GDP growth rate changes, while maintaining the current capacity of municipal wastewater treatment unchanged. During the years 2010 and 2020, the turning point appears at time point of 2017 in these three curves; urban water pollution shows a rising trend after first cut, presenting U-shape. It demonstrates that the current municipal wastewater treatment capacity will alleviate the environmental pollution to some extent. But in the long term (2020-2030), when GDP is at the high growth level of $10 \%$, water pollution (the cumulative amount of untreated

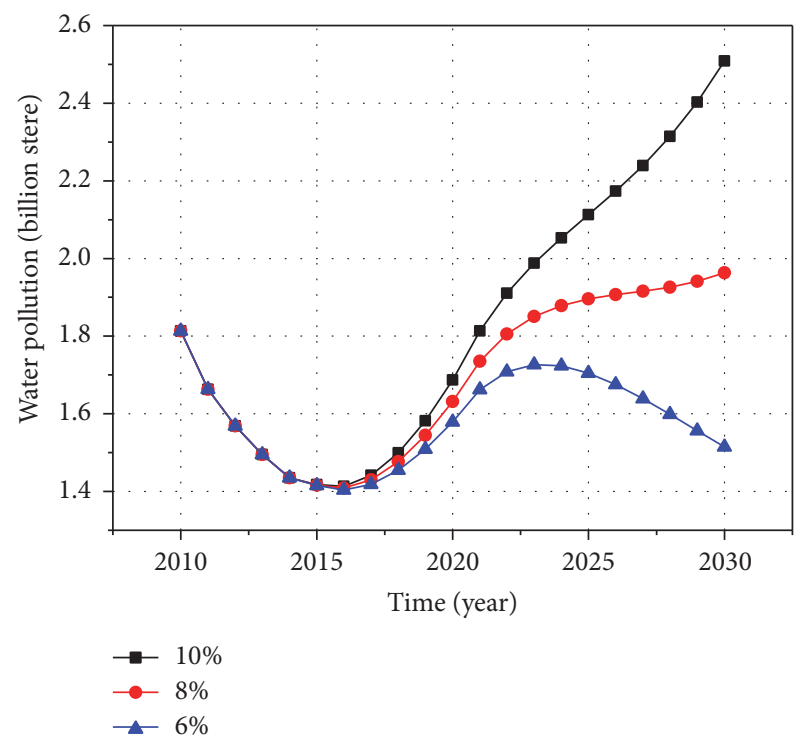

FiguRE 7: Water pollution under different GDP growth rate.

wastewater) shows a growing trend; when GDP growth rate keeps at current $8 \%$, water pollution gradually becomes stable after 2025; when GDP growth rate decreases to the low level of $6 \%$, water pollution appears as a turning point in 2023 , showing a trend of rising first and then falling and finally keeping to fall. By 2030, if GDP growth rate increases from the current level to $10 \%$, water pollution would increase by $27.8 \%$; if GDP growth rate decreases from the current level to $6 \%$, water pollution would decrease by $22.8 \%$. With the increase of wastewater output, when GDP growth rate of Wuhan keeps at the current level or higher than the current level, urban water pollution can be aggravated to some extent, which indicates that current municipal wastewater treatment capacity cannot meet the requirements of environment-friendly society and needs to be expanded.

(2) Water Consumption of Annual Ten Thousand Yuan GDP. GDP (ten thousand yuan) water consumption is another important factor affecting the amount of wastewater output, and it is related to the way of economic growth, the industrial structure of the region, the level of production equipment, and natural conditions.

Figure 8 shows that municipal wastewater changes are caused by different magnitude of water consumption of annual ten thousand GDP $\left(35 \mathrm{~m}^{3}, 30 \mathrm{~m}^{3}\right.$, and $\left.25 \mathrm{~m}^{3}\right)$. In the case of more extensive use of water resources, output of wastewater increases significantly. Compared to the current level of high water consumption, by 2030, when the GDP growth rate is $8 \%$, the increase of the wastewater treatment fee is $37.5 \%$, at the situation of resource saving (then thousand yuan GDP water consumption is $30 \mathrm{~m}^{3}$ and $25 \mathrm{~m}^{3}$ ), and the wastewater output of the whole city decreases by $6.0 \%$ and $12.0 \%$, which is a great relief to the wastewater treatment system.

When other variables (GDP growth rate, wastewater treatment fee) are all kept at the current level, the total amount of water pollution can be reduced significantly as 


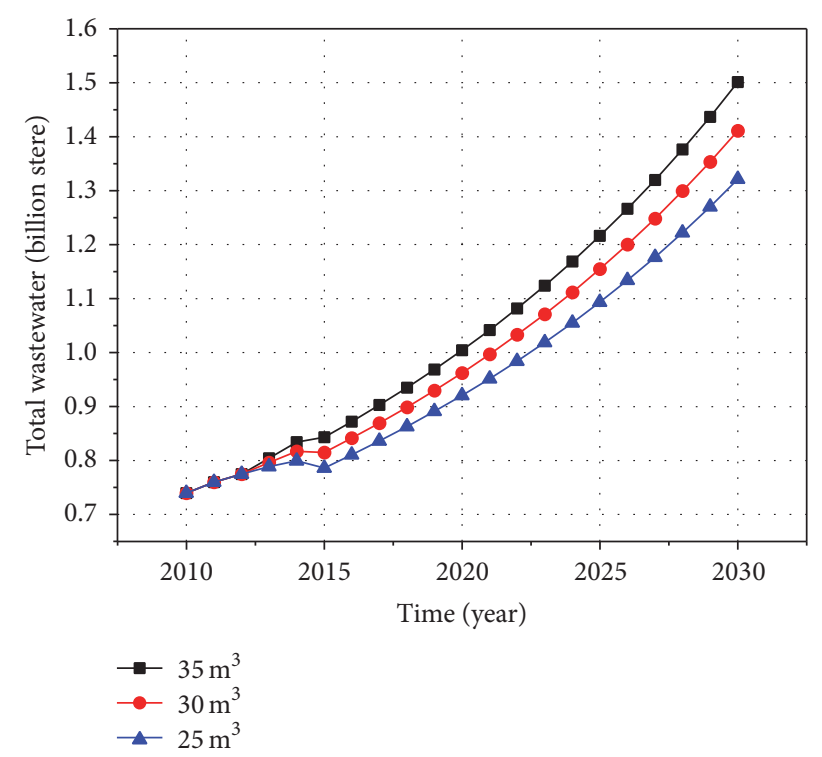

FIGURE 8: Total wastewater under different per ten thousand yuan GDP water consumption.

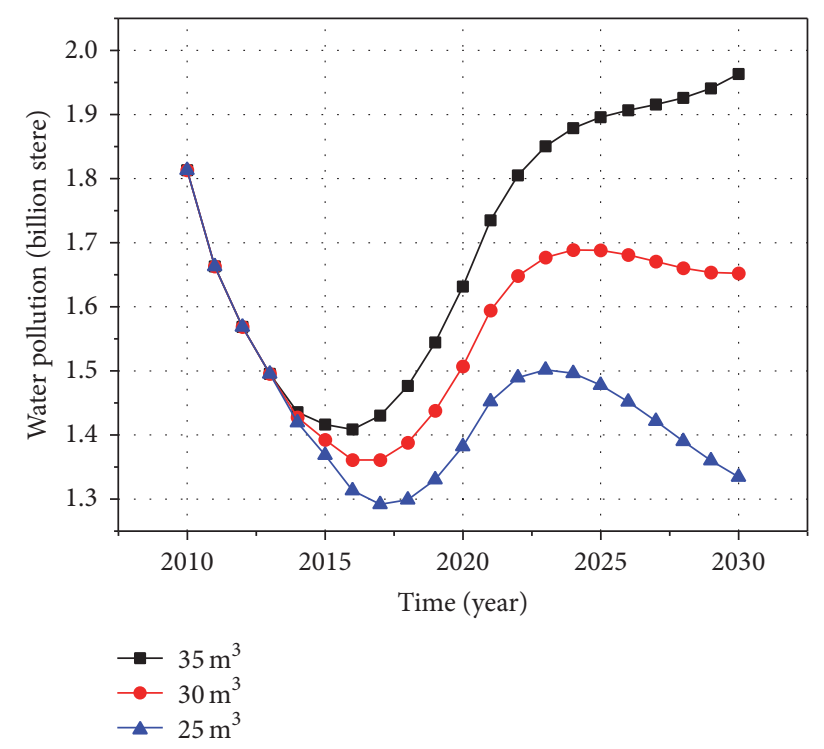

FIGURE 9: Water pollution under different per ten thousand yuan GDP water consumption.

soon as the implementation of the policy of water consumption reduction. Moreover, the more the water consumption is reduced, the more obvious the water pollution is. By 2030, due to the reduction of GDP water consumption (ten thousand yuan), decreasing from $35 \mathrm{~m}^{3}$ to $30 \mathrm{~m}^{3}$ and $25 \mathrm{~m}^{3}$,respectively, the total amount of water pollution reduces by $15.8 \%$ and $32.0 \%$, respectively. As seen in Figure 9, during the years 2010 and 2020, the three curves show a trend of decrease first and then increase. The difference is that the greater the GDP water consumption (ten thousand yuan) is, the earlier the turning point appears. This is because the water pollution is a status variable in the model and its accumulation depends on the input and output of status

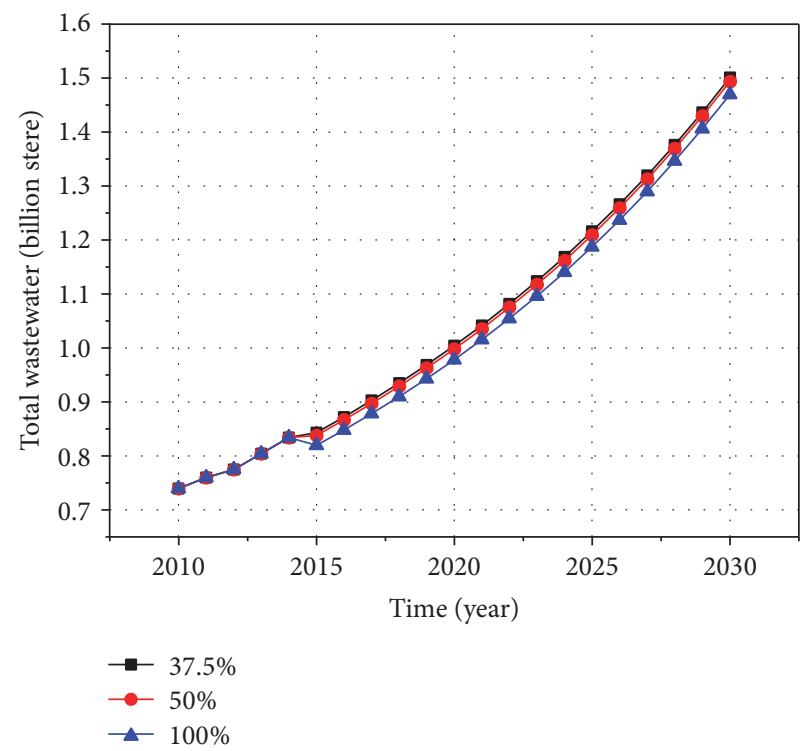

FIGURE 10: Total wastewater under different wastewater treatment fee.

variables. The increase of water consumption leads to the increase of input, and the output depends on the selfpurification capacity of water bodies and it has little changes to some extent and can be seen as a fixed value, so the status variables can grow rapidly. In the long term (2020-2030), high water consumption $\left(35 \mathrm{~m}^{3}\right)$ leads to a rapid rise in water pollution, and the rise speed becomes slow and trends to stable after 2025; the rise speed under the medium water consumption $\left(30 \mathrm{~m}^{3}\right)$ is lower than that under high water consumption, and the speed begins to slow down after 2024; under the situation of low water consumption $\left(25 \mathrm{~m}^{3}\right)$, after the year 2020, water pollution experiences 3 years of rising and then begins to drop quickly. It can be seen that reducing the water consumption per unit output value is important way to reduce wastewater output and water pollution and it is a major measure of clean production process for enterprises. In the process of wastewater treatment, both source control and end treatment should be paid attention to.

(3) Wastewater Treatment Fee. With the continuous expansion of the water industry marketization in China, the pricing of the wastewater treatment fee is getting more and more attention. Reasonable pricing can bring a certain income for wastewater treatment enterprise to ensure its normal operation and also can indirectly encourage the implementation of water-saving measures. In this section, the influence of wastewater treatment fee on the future amount of wastewater and the situation of water pollution in the city in this case is analyzed. As shown in Figure 10, when the increase of wastewater treatment fee is added from $37.5 \%$ to $50 \%$ and $100 \%$, respectively, the total amount of wastewater decreases to some extent (by $0.5 \%$ and $2.1 \%$, resp.) during the period of policy simulation; the greater the increase is, the more obvious the wastewater amount decreases. For water pollution, the increase of wastewater treatment fee can also bring significant benefits. Similar to other two control factors, 


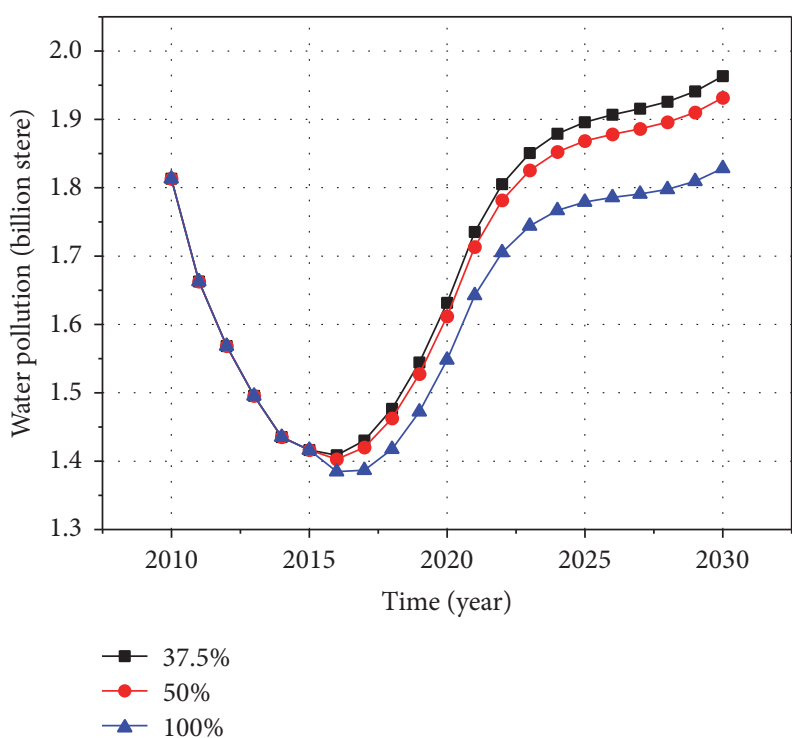

FIGURE 11: Water pollution under different wastewater treatment fee.

the influence curve of wastewater treatment fee on water pollution shows a trend of decrease first and then increase. The control role of the wastewater treatment fee to water pollution is relatively weak; the water pollution under three situations of different wastewater treatment fees shows a trend of decrease during the years 2020 and 2030 as shown in Figure 11. In general, the increases of wastewater treatment fee to some extent can restraint the aggravation of water pollution although its influence is limited.

Meanwhile, make longitudinal comparison to the three control factors selected in this article; changing such three factors can reduce the total amount of wastewater and restraint water pollution to some extent, and the influence of the wastewater treatment fee is the smallest.

(4) Different Development Modes. Finally, the future development modes of Wuhan are summarized as high-growth, high water consumption (H-H; scenario 1); high-growth, low water consumption (H-L; scenario 2); low growth, high water consumption (L-H; scenario 8), and low-growth, low water consumption (L-L; scenario 9). Under the situation of $\mathrm{H}-\mathrm{H}$, the total amount of wastewater in the future gets the fastest growth and it increases by $50.6 \%$ in 2030 when comparing with that in 2015; under the situation of L-L, it gets the slowest growth and it increases by $34.9 \%$ when comparing with that in 2015; the growth rate of wastewater during the years 2015 and 2023 under the situation of $\mathrm{H}-\mathrm{L}$ is lower than that of $\mathrm{L}-\mathrm{H}$, but during the years 2023 and 2030, it will be higher than that of L-H. By 2030, the total amount of wastewater in Wuhan under different situations is sorted by size as follows: $\mathrm{H}-\mathrm{H}>$ $\mathrm{H}-\mathrm{L}>\mathrm{L}-\mathrm{H}>\mathrm{L}-\mathrm{L}$. Comparing the situations of $\mathrm{H}-\mathrm{L}$ and $\mathrm{L}-\mathrm{H}$, it can be seen in Figure 12 that the influence of GDP water consumption (then thousand yuan) to the total amount of wastewater is greater than that of GDP growth rate in the near future (2015-2023), and the influence of GDP growth rate is more obvious in the long term (2023-2030).

As shown in Figure 13, urban wastewater under different development model presents great differences. Under the

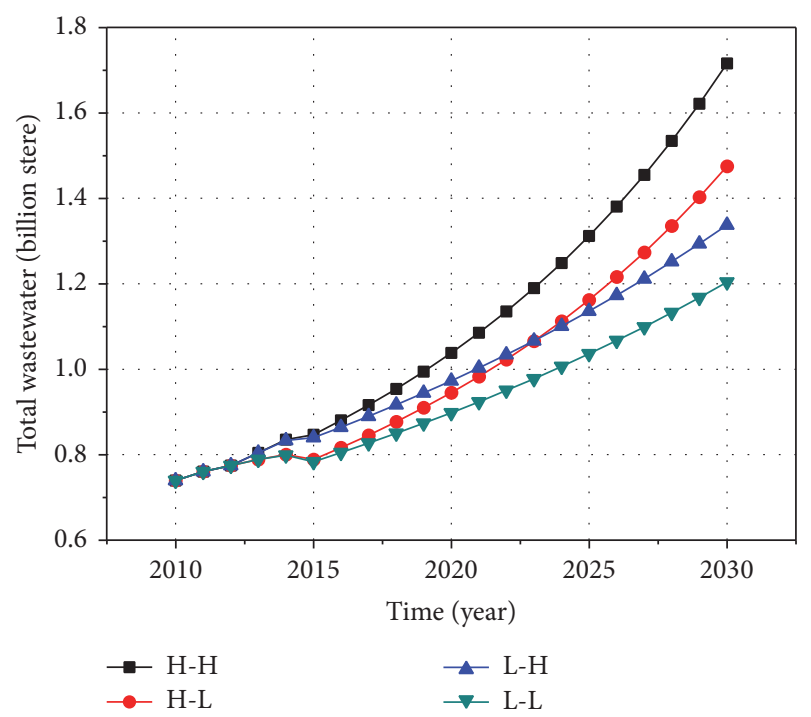

FIgURE 12: Total wastewater under different development patterns.

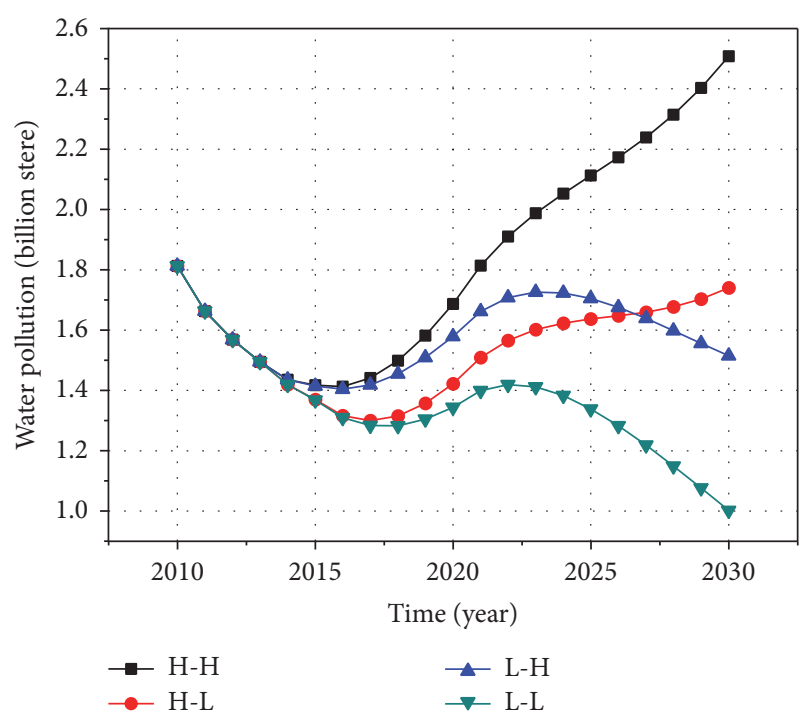

FIGURE 13: Water pollution under different development patterns.

development model of low economic growth, water pollution experiences a process of "decrease-increase-decrease" in the simulation period (2015-2030) and it presents a trend of decrease in the long term; but under two development models of high economic growth, water pollution presents a process of "decrease-increase" and finally presents a trend of increase and becomes stable. Thus, it can be seen that the wastewater treatment capacity of Wuhan would not meet current wastewater treatment needs and water pollution would continue to be aggravated if under the situation of high economic development. The two curves of $\mathrm{H}-\mathrm{L}$ and $\mathrm{L}-\mathrm{H}$ are analyzed and the intersection point appears in the year 2027. Before 2027, the water pollution under the development model of $\mathrm{L}-\mathrm{H}$ is more serious than that of $\mathrm{H}$ L. After 2027, the water pollution presents a trend of rising under the development model of $\mathrm{H}-\mathrm{L}$ and dropping under the development model of L-H. In the long term, the influence of economic development to water pollution is greater. 


\section{Conclusion}

The current work systematically investigated the socioeconomic, municipal wastewater, and urban water environment by the system dynamics for the first time, which provided a new strategy for the management of municipal wastewater system. In addition, it also offers the overlook of dynamic change of the whole system and the theoretical foundation to the management to make the right decision. Based on the discussion above, it can be concluded as follows:

(1) The factors affecting the sustainable development of the municipal wastewater system and their relationship and feedback mechanism were investigated. Based on the results, a SD model for the sustainable municipal wastewater system was developed from the socioeconomic, municipal wastewater, and urban water environment to simulate the future municipal wastewater and to explore the key factors that affect the municipal wastewater system.

(2) The reliability of the SD model was demonstrated by case study. The SD model was able to effectively simulate the real system, even the system with insufficient historical data, by the combination of qualitative and quantitative analyses. The dynamics simulation of municipal wastewater is an important part of urban water pollution control and management. It is significant for reducing pollution, ensuring the health of urban water environment, improving the life quality of the urban residents, and achieving the sustainable development.

(3) The case study also indicated that the municipal wastewater increased with the growth of GDP and increasing the wastewater treatment fee could significantly reduce the emission of wastewater. The municipal wastewater and water pollution increase most rapidly in the scenario of rapid economic growth and extensive resource utilization, and thus it cannot blindly pursue economic growth while ignoring resource conservation.

(4) The SD model was used to evaluate the sustainable development of the municipal wastewater using GDP growth rate, water consumption of annual ten thousand GDP, and wastewater treatment fee as the control variables. The results indicated that, compared with the GDP growth rate, the water consumption per ten thousand GDP affected the municipal wastewater more significantly in the short term. However, the influence of GDP growth rate was more obvious in the long term. Therefore, the effective implementation of water conservation measures is an efficient way to reduce the emission of wastewater and to eventually realize the environment-friendly wastewater system.

\section{Competing Interests}

The authors declare that there are no competing interests regarding the publication of this paper.

\section{Acknowledgments}

The project was financed by the National Natural Science Foundation of China (Grant no. 71390524). The authors would like to thank Professor Minhui Yu in School of Automation, Huazhong University of Science and Technology, for his guidance in developing the SD model, and Wuhan Urban Drainage Development Co., Ltd., for its basic data.

\section{References}

[1] T. Panayotou, Empirical Tests and Policy Analysis of Environmental Degradation at Different Stages of Economic Development, vol. 4 of Ilo Working Papers, International Labour Office, 1993.

[2] S. Dawadi and S. Ahmad, "Evaluating the impact of demandside management on water resources under changing climatic conditions and increasing population," Journal of Environmental Management, vol. 114, pp. 261-275, 2013.

[3] I. Cazcarro, R. Duarte, and J. Sánchez-Chóliz, "Economic growth and the evolution of water consumption in Spain: a structural decomposition analysis," Ecological Economics, vol. 96, pp. 51-61, 2013.

[4] R. Duarte, J. Sánchez-Chóliz, and J. Bielsa, "Water use in the Spanish economy: an input-output approach," Ecological Economics, vol. 43, no. 1, pp. 71-85, 2002.

[5] T. Okadera, M. Watanabe, and K. Q. Xu, "Analysis of water demand and water pollutant discharge using a regional inputoutput table: an application to the City of Chongqing, upstream of the Three Gorges Dam in China," Ecological Economics, vol. 58, no. 2, pp. 221-237, 2006.

[6] W. Wang, L. Gao, P. Liu, and A. Hailu, "Relationships between regional economic sectors and water use in a water-scarce area in China: a quantitative analysis," Journal of Hydrology, vol. 515, pp. 180-190, 2014.

[7] M. S. Babel, A. D. Gupta, and P. Pradhan, "A multivariate econometric approach for domestic water demand modeling: an application to Kathmandu, Nepal," Water Resources Management, vol. 21, no. 3, pp. 573-589, 2007.

[8] Y. Bai, P. Wang, C. Li, J. Xie, and Y. Wang, "A multi-scale relevance vector regression approach for daily urban water demand forecasting," Journal of Hydrology, vol. 517, pp. 236-245, 2014.

[9] S. Alvisi, M. Franchini, and A. Marinelli, "A short-term, patternbased model for water-demand forecasting," Journal of Hydroinformatics, vol. 9, no. 1, pp. 39-50, 2007.

[10] Y. Cai, "Forecasting for quantile self-exciting threshold autoregressive time series models," Biometrika, vol. 97, no. 1, pp. 199208, 2010.

[11] G. J. Bowden, G. C. Dandy, and H. R. Maier, "Input determination for neural network models in water resources applications. Part 1-background and methodology," Journal of Hydrology, vol. 301, no. 1-4, pp. 75-92, 2005.

[12] C. Bennett, R. A. Stewart, and C. D. Beal, "ANN-based residential water end-use demand forecasting model," Expert Systems with Applications, vol. 40, no. 4, pp. 1014-1023, 2013.

[13] M. Firat, M. E. Turan, and M. A. Yurdusev, "Comparative analysis of neural network techniques for predicting water consumption time series," Journal of Hydrology, vol. 384, no. 1-2, pp. $46-51,2010$. 
[14] S. Ahmad and D. Prashar, "Evaluating municipal water conservation policies using a dynamic simulation model," Water Resources Management, vol. 24, no. 13, pp. 3371-3395, 2010.

[15] X. Xi and K. L. Poh, "Using system dynamics for sustainable water resources management in Singapore," in 11th Annual Conference on Systems Engineering Research, CSER 2013, pp. 157-166, usa, March 2013.

[16] E. G. R. Davies and S. P. Simonovic, "Global water resources modeling with an integrated model of the social-economicenvironmental system," Advances in Water Resources, vol. 34, no. 6, pp. 684-700, 2011.

[17] H. C. Guo, L. Liu, G. H. Huang, G. A. Fuller, R. Zou, and Y. Y. Yin, "A system dynamics approach for regional environmental planning and management: A Study for The Lake Erhai Basin," Journal of Environmental Management, vol. 61, no. 1, pp. 93-111, 2001.

[18] J. Zhu, X. Wang, L. Zhang, H. Cheng, and Z. Yang, "System dynamics modeling of the influence of the TN/TP concentrations in socioeconomic water on NDVI in shallow lakes," Ecological Engineering, vol. 76, pp. 27-35, 2015.

[19] O. Sahin, R. A. Stewart, and M. G. Porter, "Water security through scarcity pricing and reverse osmosis: a system dynamics approach," Journal of Cleaner Production, vol. 88, pp. 160-171, 2015.

[20] M. Zarghami and S. Akbariyeh, "System dynamics modeling for complex urban water systems: application to the city of Tabriz, Iran," Resources, Conservation and Recycling, vol. 60, pp. 99-106, 2012.

[21] A. C. Kelley and R. M. Schmidt, "Aggregate population and economic growth correlations: the role of the components of demographic changes," Demography, vol. 32, no. 4, pp. 543-555, 1995.

[22] R. M. Solow, "A contribution to the theory of economic growth," The Quarterly Journal of Economics, vol. 70, no. 1, pp. 65-94, 1956.

[23] W. D. Nordhaus and M. L. Weitzman, "Lethal model 2: the limits to growth revisited," Brookings Papers on Economic Activity, vol. 23, no. 2, pp. 1-59, 1969.

[24] A. Bruvoll, S. Glomsrød, and H. Vennemo, "Environmental drag: evidence from norway," Ecological Economics, vol. 30, no. 2, pp. 235-249, 1999.

[25] Q. Zhang, H. F. Xue, H. Z. Dong, and R. Liu, "Empirical research on the relationship between the regional economic development and environmental pollution," China. Statistics \&Decision, no. 7, pp. 77-79, 2009.

[26] G. Li, "The analysis of the blocking effect to economic growth under the constraints of resource and environment," China. Chin. Econ., no. 4, pp. 28-33, 2008.

[27] A. Ruijs, A. Zimmermann, and M. van den Berg, "Demand and distributional effects of water pricing policies," Ecological Economics, vol. 66, no. 2-3, pp. 506-516, 2008.

[28] S. M. Olmstead, W. M. Hanemann, and R. N. Stavins, "Water demand under alternative price structures," Journal of Environmental Economics and Management, vol. 54, no. 2, pp. 181-198, 2007.

[29] Y. Barlas, "Formal aspects of model validity and validation in system dynamics," System Dynamics Review, vol. 12, no. 3, pp. 183-210, 1996.

[30] Wuhan Government. The population.

[31] Wuhan Government, The natural resource.

[32] Wuhan Bureau of Statistics. Statistical Yearbook.
[33] R. Oliva, "Model calibration as a testing strategy for system dynamics models," European Journal of Operational Research, vol. 151, no. 3, pp. 552-568, 2003. 


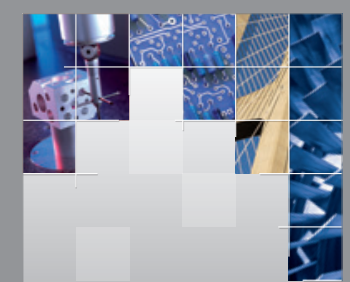

\section{Enfincering}
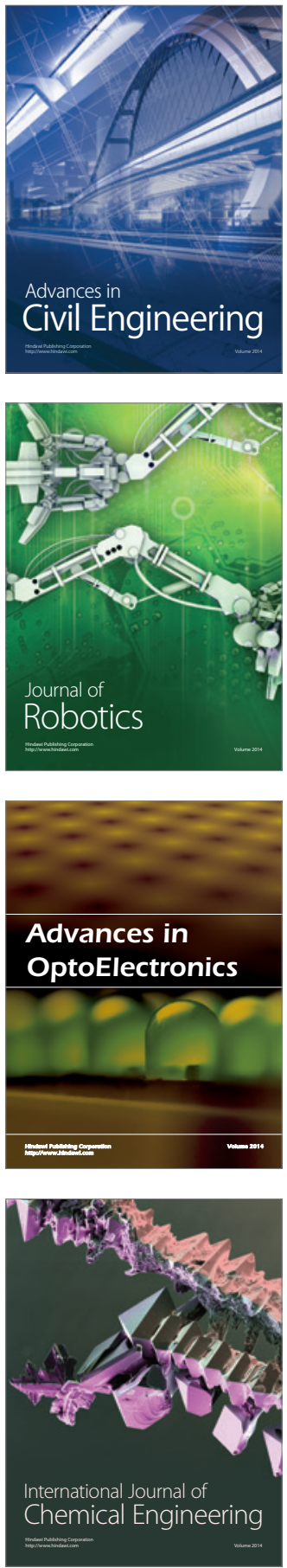

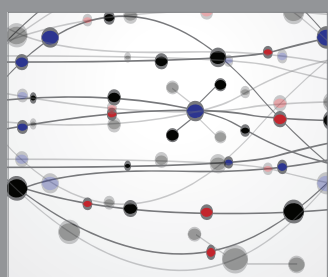

The Scientific World Journal

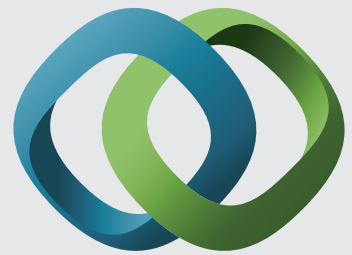

\section{Hindawi}

Submit your manuscripts at

http://www.hindawi.com
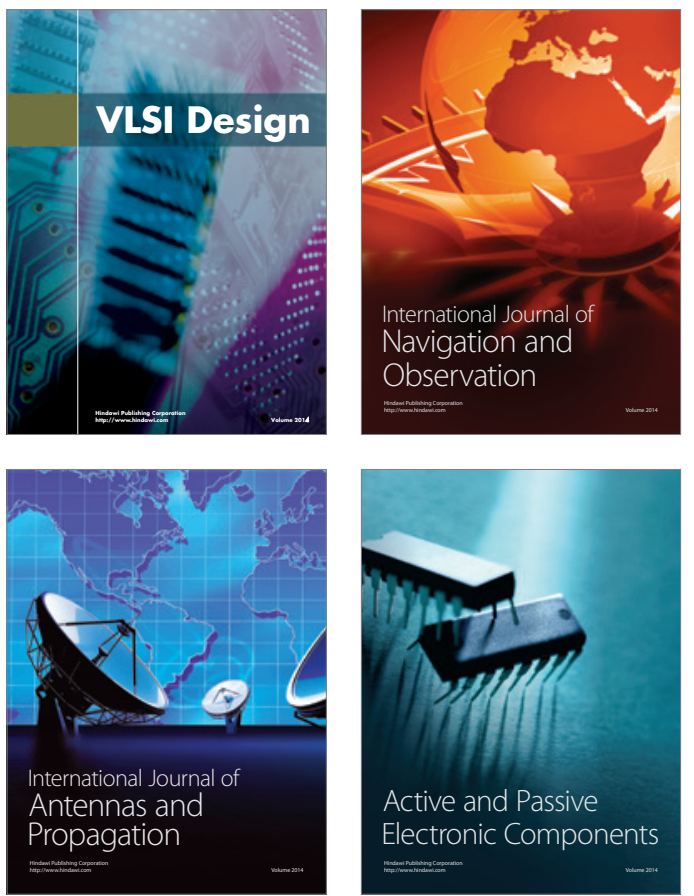
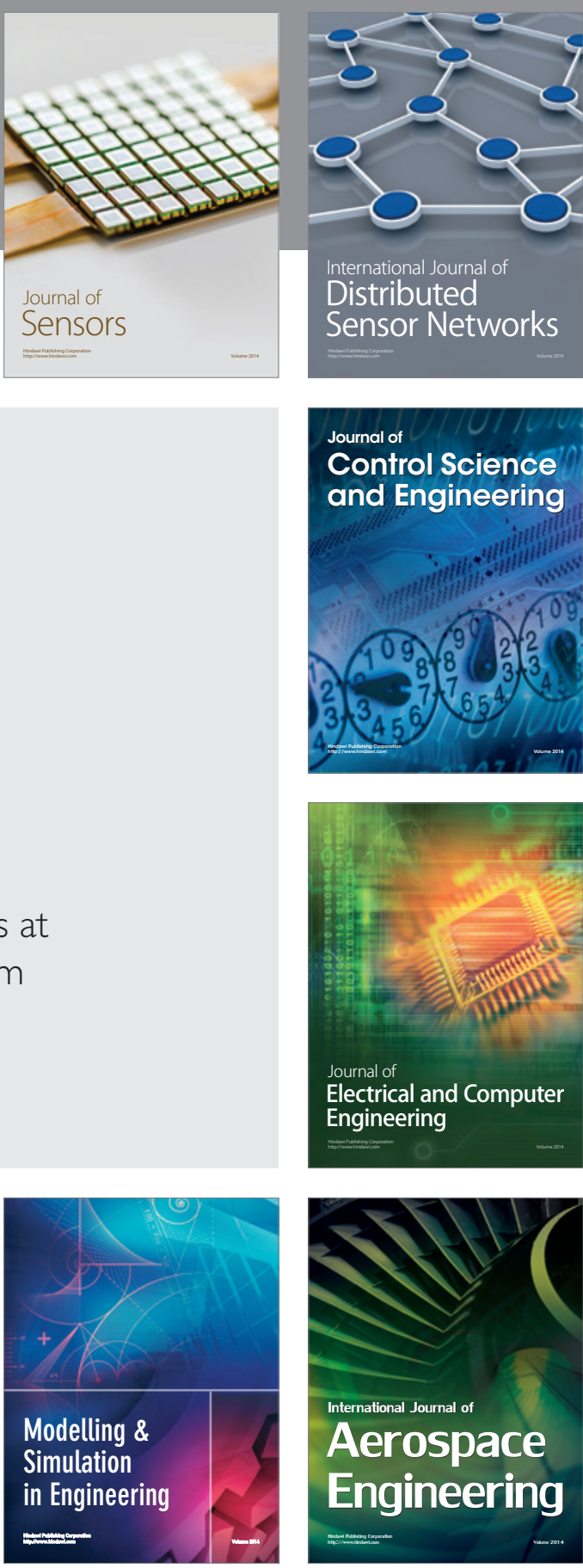

International Journal of

Distributed

Sensor Networks

Journal of

Control Science

and Engineering
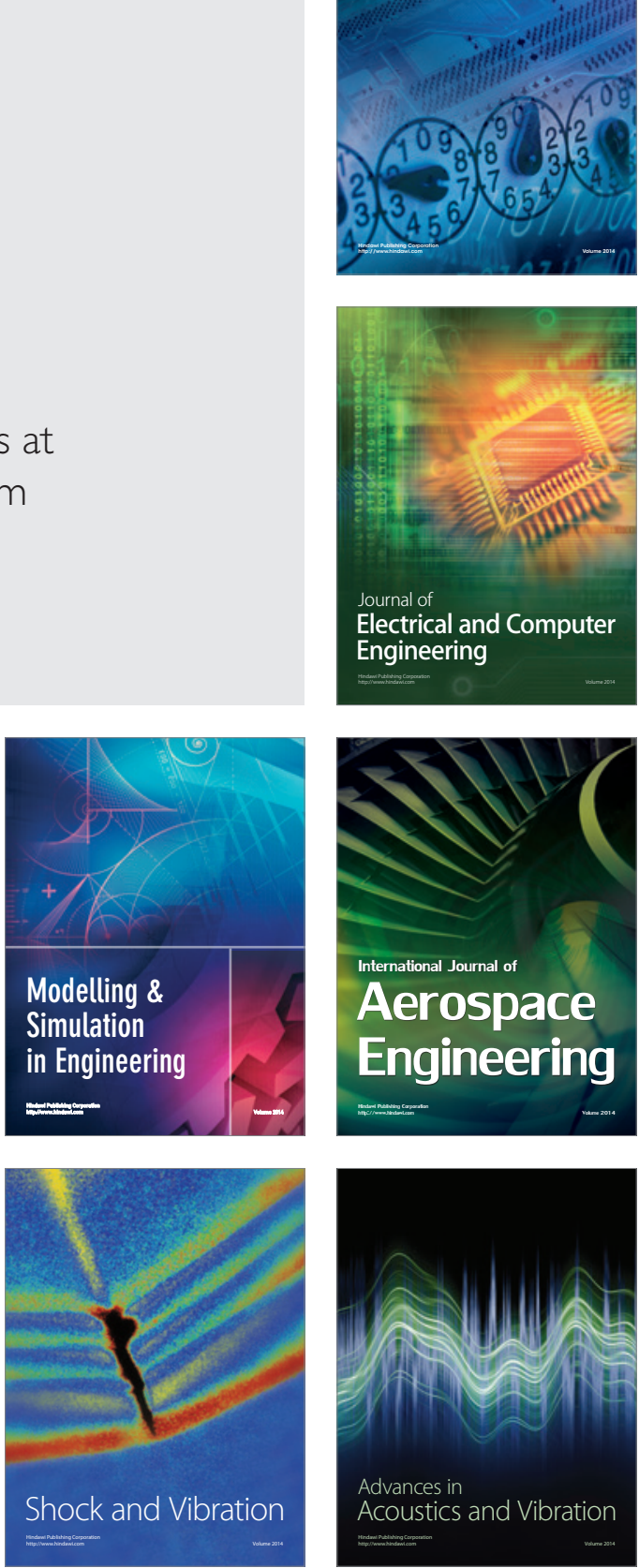